\title{
Correction to: Tenebrio molitor in the circular economy: a novel approach for plastic valorisation and PHA biological recovery
}

\author{
Paola Sangiorgio $^{1}$ (i) $\cdot$ Alessandra Verardi $^{1} \cdot$ Salvatore Dimatteo $^{1} \cdot$ Anna Spagnoletta $^{1} \cdot$ Stefania Moliterni ${ }^{1}$. \\ Simona Errico ${ }^{1}$
}

Published online: 6 November 2021

(c) Springer-Verlag GmbH Germany, part of Springer Nature 2021

Correction to: Environmental Science and Pollution Research (2021) 28:52689-52701

https://doi.org/10.1007/s11356-021-15944-6

We realized that the sentence at pg 52691, second column, lines 4-6:

"TM authorization for ruminants (e.g. sheep and cattle) and monogastric animals (e.g. pigs and poultry) is expected by the end of 2021" contains a misleading and out-of-date information. It should be corrected with:

"Recently, the Commission (EU) 2021/1372 also authorized the use of insect-derived proteins for poultry and pigs."

Publisher's note Springer Nature remains neutral with regard to jurisdictional claims in published maps and institutional affiliations.

The original article can be found online at https://doi.org/10.1007/ s11356-021-15944-6.

Paola Sangiorgio paola.sangiorgio@enea.it

1 ENEA Italian National Agency for New Technologies, Energy and Sustainable Economic Development,

Trisaia Research Centre, S.S. 106 Jonica, km 419,500,

75026 Rotondella, MT, Italy 